\title{
IMÁGENES RADICALES COMPROMETIDAS EN LAS SITUACIONES INMEDIATAS DE LA PRODUCCIÓN DEL CONSEJO TÉCNICO ESCOLAR
}

RADICAL IMAGES COMMITTED IN THE IMMEDIATE SITUATIONS OF THE PRODUCTION OF THE TECHNICAL SCHOOL COUNCIL

\author{
- \\ Florentino Silva Becerra \\ cienaga16m@hotmail.com \\ María Guadalupe Moreno Bayardo \\ gpemor198@hotmail.com \\ Guadalajara. Campus Belenes. Jalisco, México.
}

Departamento de Estudios en Educación del Centro Universitario

de Ciencias Sociales y Humanidades de la Universidad de 
Para citar este artículo:

Silva-Becerra, Florentino, Moreno-Bayardo, María. (2019). Imágenes radicales comprometidas en las situaciones inmediatas de la producción del consejo técnico escolar. Espacio I+D, Innovación más Desarrollo. VIII(21), 118-133. doi: http://dx.doi. org/10.31644/IMASD.21.2019.a07

\section{RESUMEN}

Este trabajo presenta, desde la relación de lo social, lo que los profesores y directivos construyen en el Consejo Técnico Escolar; la construcción de significados que a través de la interacción comparten; por lo que se pregunta ¿cuáles son los símbolos que se producen en las interacciones que le dan sentido al colegiado de los profesores y directivos? ¿Cuáles son las imágenes que se describen en la actuación colegiada y el significado que representan en el comportamiento del grupo? El objetivo es interpretar la producción de sentido que se genera en las imágenes de la interacción colegiada que describen el significado de la actuación de los profesores y directivos en el Consejo Técnico Escolar.

El enfoque definido del estudio de la vida de los grupos humanos y de su comportamiento sustentado en la perspectiva teórica de la interacción social, desde la concepción del significado que surge como consecuencia de la colegialidad que cada cual mantiene con el otro, y que se modifican mediante la interpretación de la producción social in situ, guía este proceso la metodología de investigación social bajo el enfoque explicativo de la teoría fundamentada, el muestreo teórico como herramienta para la recogida de datos sucesivos, comenzando con códigos abiertos sobre los datos recogidos para determinar nuevos fenómenos para su análisis, los resultados son fundamentales para sucesivos procesos de investigación.

Como resultantes tenemos que los significados en la interacción colegiada de profesores y directivos tiene como base la interconexión dinámica, donde los símbolos que emergen de los actos interactivos son una dotación expresiva en un marco de lo que supone la creación de normas propias del contexto donde los "performances", los actores mediante los símbolos que emergen de los actos interactivos, reproducen una dotación expresiva de estas escenas culturales.

\section{Palabras clave}

Consejo Técnico Escolar; influencias recíprocas; imágenes radicales; significados compartidos y sentido. 
This work presents from the relationship of the social thing that the professors and directors construct in the Technical School Council; the construction of meanings that through interaction they share; so he asks himself; What are the symbols that occur in the interactions that give meaning to the collegiate of teachers and managers? What are the images that are described in the collegiate performance and the meaning they represent in the behavior of the group? The objective; interpret the production of meaning that is generated in the images of collegiate interaction that describe the meaning of the actions of teachers and managers in the School Technical Council.

The defined focus of the study of the life of human groups and their behavior based on the theoretical perspective of social interaction, from the conception of meaning that arises as a consequence of the collegiality that each one maintains with the other, and that these modify through the interpretation of social production in situ, this process guides the social research methodology under the explanatory approach of the grounded theory, the theoretical sampling as a tool for the collection of successive data, starting with open codes on the data collected to determine new phenomena for its analysis, the results are foundations for successive research processes.

As result we have that the meanings in the collegial interaction of professors and managers is based on the dynamic interconnection where the symbols that emerge from the interactive acts, are an expressive endowment in a framework of what the creation of own norms of the context supposes. "Performances", the actors through the symbols that emerge from the interactive acts are producing an expressive endowment of these cultural scenes.

\section{Keywords}

School Technical Council, reciprocal influences, radical images, shared meanings and meaning. 
$\mathrm{E}$ 1 contexto social de la vida escolar se hace posible en la medida en que se construye una intersección entre sentidos en la interacción; aquellos imputados a las acciones de los participantes en el colegiado del Consejo Técnico Escolar. Los vínculos que persisten, muchas veces resumen las luchas por el control de la organización escolar. Interés de éstas son las interacciones de negociación, que a través de las relaciones diádicas acceden al encastre estructurante de esa complejidad.

Simmel (2002), desde su teoría, busca la comprensión de estas formas sociales no institucionalizadas, como la diádica, generada por la acción recíproca de dos actores insertos en un entramado de relaciones y sentidos compartidos, situación dialógica que va más allá de la forma individual de pensar.

La fijación de fronteras, como ordenamiento territorial de las estructuras de la comunicación en la interacción colectiva, agrupa a profesores y directivos, convirtiendo los espacios colegiados en aduanas que no admiten modificaciones a sus acciones colectivas, integradas al sentido del objeto de la actividad escolar, transformando la colegialidad en una realidad compleja que reacciona a las transiciones que generan los nuevos cambios educativos.

Pero ¿Cuál es el significado que tiene para el colectivo de profesores y directivos la interacción colegiada?

En esta encrucijada, el conjunto de relaciones establecidas por los profesores y directivos en colegiado, permite distinguir las transacciones que permean el contexto, un orden negociado, espacio normativo para instituir la forma de participar; categoría social de articulación de las interacciones colectivas, por lo que la dialogicidad in situ se suma a la constitución de un orden social estructurante, la acción social participa de la interacción de los integrantes del CTE, mediante la construcción de un mundo de formas simbólicas en el significado que se refleja en el control organizativo encubierto por el consenso de la interacción social, que se apodera de la colegialización, generando una integración de sentido que usa la comunicación para transmitir sus significados en contexto, contribuyendo fundamentalmente a la reproducción del orden social, emergiendo símbolos de identidad compartidos por el grupo, constituyéndose en una red pre-existente de estructuras que reconfiguran y fortalecen su patrón de relaciones de la producción social in situ, estructurando rasgos distintivos de la colegialización, una concepción de conjunto del mundo social y del lugar en él que ocupan las relaciones y las redes que los identifican.

\section{MÉTODO}

Para la comprensión de la realidad en la construcción de las interacciones sociales se abordó la siguiente metodología: 


\section{a). -Sujetos}

Se parte de la selección de las interacciones diádicas como espacio vivido en un orden social y negociación, elegidos por su posible relevancia en la realización de proyectos anteriores.

La recogida de los datos va configurando el dominio de la muestra en relación con la teoría, generando con esto que la muestra sea un procedimiento abierto y ad hoc y no un parámetro a priori del diseño.

En esta muestra por conveniencia, se contó con 13 profesores de educación física y 16 profesores de artes, 2 coordinadores y 2 directivos, todos pertenecientes a una zona escolar de educación secundaria pública conducidos por el director.

b). - El muestreo teórico generó la recogida de datos mediante los instrumentos: la observación participante en los mismos escenarios en que acontecen las interacciones; entrevistas, diseñadas en una primera fase, seleccionándose los casos por sus semejanzas, posteriormente se eligieron por sus diferencias, la creación de categorías se establece por sus semejanzas.

c). - Hipótesis, éstas se generan desde el momento en que emergen los datos, el diseño de investigación basado en el enfoque de la teoría fundamentada requiere iniciar la generación de la teoría sin hipótesis, ni ideas preconcebidas sobre el objeto de estudio. El proceso da inicio con códigos abiertos sobre los datos recogidos, por lo que la muestra selectiva se dirige hacia los temas que son centrales.

d). - El contexto

Este está enmarcado por sesiones del Consejo Técnico Escolar denominada aprendizaje entre iguales, en el cual se dan cita profesores de 12 escuelas secundarias pertenecientes a las asignaturas de Artes y Educación Física, conjunto que como categoría social, es un grupo que se percibe a sí mismo integrado por profesores y directivos que han desarrollado una "conciencia de nosotros". No es sólo un grupo de pertenencia, al que el sujeto se conecta pasivamente, sino que es un grupo de referencia, en el que los sujetos utilizan normas y valores sociales para orientar su pensamiento y su actuar, en una situación dada. 


\section{RESULTADOS}

\section{a).-Significados establecidos}

Dice Blúmer (1982) que el significado que las cosas encierran para el ser humano un elemento central en sí mismas, por lo que el significado es el fruto del proceso de interacción entre los individuos.

En la medida en que los individuos interactúan a través de sus actos, definen a sus interactuantes de acuerdo con su función, producto de la interacción social; entonces la construcción social in situ resultado de la interacción entre los profesores y directivos es el efecto de las distintas actuaciones en relación al objeto, porque los actos de los miembros del grupo provocan un corolario que define sus interacciones. A continuación se abordaran interacciones in situ producto de la interacción colectiva en el Consejo Técnico Escolar:

El colegiado asume que el inicio y presentación de la reunión le corresponde al director:

Dir.- Inicia la sesión, da la bienvenida y explica el desarrollo de la sesión, el Director organiza una observación colectiva de las clases de los profesores.

Estos significados establecidos, generados por el cauce de la marcha colegiada son el discurso de apertura de la sesión y que anuncia a los integrantes el momento la apertura de las acciones dialogizadas entre profesores y directivos, estas simbolizan la construcción de un contexto de significados compartidos, donde las definiciones de nuevos sentidos abren un espacio a la realidad social que solo se construye en la interacción con los otros:

Mo.- La sesión anterior pidió que involucraran español y matemáticas y trae material impreso de su trabajo.

El profesor manifiesta que él puede seguir con la presentación de los trabajos, es decir se encuentra la acción establecida como parte de la estructura de la sesión que cada profesor presenta al colectivo, la tarea consiste en mostrar una clase, para ser valorada mediante un instrumento de observación, el Director indica el seguimiento de la guía de observación, para el cumplimiento de la sesión:

Dir.- Comenta que se tiene que seguir con la observación.

La guía de observación a la que los profesores y directivos han de someterse es el eje central del proceso que da sentido a la interacción: 
Ma.-Dice que en el resultado puede verse el desarrollo y las preguntas si pueden ser contestadas.

Los profesores y directivos conocen el espacio del grupo porque éste los ha establecido, valores y normas que se construyen y se va integrando a la cultura que la colegiada estructura para la interacción del grupo, están implícitas y por lo tanto establecidas:

Mo.- dan su opinión de acuerdo a lo que observaron en los videos presentados.

El coordinador de los trabajos solicita las participaciones de acuerdo con el orden que se presenta en el contexto, los profesores conocen el espacio ya que es entre iguales y pueden involucrarse en la crítica de los trabajos de los participantes en turno:

Mo.-Le cuestionan a la maestra si los videos estaban en orden con un inicio un desarrollo y un cierre.

Por lo que otra profesora continua con la presentación de su trabajo, en este caso muestra unos dibujos que han elaborado sus alumnos:

Ma.- muestra sus evidencias, trabajos realizados en su clase de arte. Muestra varios trabajos de sus alumnos hechos con materiales diferentes. Todos los trabajos son con libertad en cuanto al tema.

Los profesores suman sus participaciones como producto de la interacción:

Mos.- Dieron retroalimentación a la presentación, donde mencionaron que es importante mantener el interés de los alumnos, un maestro comentó que ahora con la autonomía los alumnos tienen la oportunidad algo que sea de su interés.

La intervención del coordinador del grupo se manifiesta haciendo referencia a la pregunta ¿qué aprendimos?, genera nuevamente condiciones para que los profesores y directivos se incorporen el producto de sus acciones:

Dir.- ¿Qué aprendimos?

A lo que suma su participación de integración, para todos, el contexto en que los profesores y directivos se agregan a la acción de significados que permea a los grupos en interacción. 
Dir.- Dice que se estarán retomando estas reuniones. Tenemos que ser inclusivos.

A lo que continúa de manera selectiva invitando al colectivo a que se sume a su participación:

Mo. Dice que para él sería mejor que solo estén los maestros de educación física para intercambiar ideas.

El mediador en su responsabilidad de intervenir en la conducción de la reunión y conservar el fin que se persigue en el grupo, continúa con su insistencia:

Dir.- Debemos ser incluyentes.

Lo que trae como consecuencia la generación de imágenes personales y de grupo, actos que permitan mantener al conjunto en la interacción establecida.

Los significados establecidos se convierten en normas y valores para el colectivo, fijándose en ellos imágenes radicales que constituyen su actuar.

\section{b).- Significados manipulados}

La manipulación de significados parte de la interpretación que se manifiesta en la interacción del grupo. A continuación se describen los momentos en que los profesores y directivos hacen uso de este acto de interacción:

Mo.- Explica él que podría interesar a los alumnos para participar.

El profesor hace referencia al interés de los alumnos, éste es el eje central de la práctica docente del profesor; aquí se desprende una imagen de profesor, de ahí el manejo de las acciones, porque esto les permite la utilización del significado para proteger su participación.

Mo.- El maestro refiere que se busca sobre el interés del alumnos y adecuándolo al programa.

El poner a sus alumnos como referente, es poner lo que el grupo tiene sentido, convirtiéndose este espacio en un ambiente de significados compartidos.

Mo.- Se tiene que utilizar la empatía. Principales barreras. Profesor-alumno, adulto-adolescente mis gustos sus gustos.

La puesta en contexto de significados compartidos para los profesores, se ha convertido en principios fundamentales que no tiene contradicción, que 
generan empatía entre ellos, por lo que esto permite a los participantes sumándose a lo señalado:

Mo.- Menciona que recibió retroalimentación por parte de algunos de los padres de familia donde lo felicitaban por lo que ha logrado con los alumnos.

De esta manera todos orientan sus actos en función que se encuentran en contexto, categoría indispensable en el proceso de la práctica docente es el padre de familia, por lo que los participantes se abstraen a abordar este sentido.

Mo.- Y vuelve a mencionar que es importante ver cuáles son los intereses de los alumnos, menciona que él trabajaba en un rancho y tenía que caminar cinco kilómetros y en ese trayecto.

El mismo profesor continúo enfatizando el interés que muestran los alumnos en su clase, mediante la inclusión al tomarlos en cuenta:

Mo.- Uno de los alumnos que más se involucra actualmente en artes porque se ha interesado en él.

Y el mismo mide los resultados:

Mo.- Me da gusto ver los avances que ha visto en sus alumnos.

El significado derivado de las imágenes que se desprenden de la interacción colectiva. Continúa refiriéndose a sus alumnos:

Mo.-Desde que inició siempre le echa muchas ganas

Un maestro participa en torno a su exposición diciendo:

Mo.- Entonces los maestros están mal.

Ya que el que manifiesta su discurso tiende a dividir al grupo. El colectivo encierra un significado al cual contesta:

Mo.- Lo está viendo desde su experiencia que no se está metiendo con el trabajo de los demás los que está compartiendo lo que le ha funcionado en su trabajo en la escuela solo eso.

La intervención de una profesora pide explicaciones: 
Ma.- En el fondo del video hay unas pinturas y pide que le platique de qué se trata el proyecto.

El profesor sigue mostrando lo mejor de sus actuaciones:

Mo.- A lo que el maestro contesta poniendo otro video del encuentro estatal donde participaron bailando.

Surge un planteamiento ante la presentación del alumno con capacidades diferentes en el aprendizaje:

Ma.-Cómo logra homogeneizar al grupo donde le cuesta trabajo.

La profesora da respuesta al cuestionamiento:

Ma.- La maestra dice que se trabaja en equipos para integrarlos y que ellos elijan el equipo en el que quieran estar.

Continúa la participación sumándose a los que están estructurados en símbolos producto de la interacción, la interconexión entre participantes, el planteamiento para integrarse, incluyendo al niño con capacidades diferentes:

Ma.- Otra dice que cuando deja que se juntan como ellos quieren lleva a la indisciplina.

Permiten la construcción de imágenes del deber ser y que todos paren adoptar:

Ma.- contesta que sí pero en ese momento para la actividad y dialoga con ellos.

Y continúa, enfatizando el éxito en su práctica docente:

Ma.- También dice que viene la parte de la negociación y solicita de acuerdo a las características del alumno le pide que haga ciertas actividades.

Interviene el coordinador de la sesión para indicar los rasgos de la guía de observación, donde el colectivo evalúa la participación:

DIR.- Se remite a la guía para ver unos puntos. Otro maestro dice que la educación física ha cambiado y que en estos tiempos ya es otra cosa. Nuevamente el director 
hace la dinámica que se hizo con anterioridad para con la materia de artes realizando las preguntas de la guía.

La voz del coordinador del grupo enfatiza los rasgos de la guía de observación:

Mo.-Dan su opinión de acuerdo a lo que observaron en los videos presentados.

Surgen cuestionamientos a su práctica en el momento de la evaluación:

Mo.-Le cuestionan a la maestra si los videos estaban en orden con un inicio un desarrollo y un cierre.

Se consolida el proceso, los maestros proponen como acción la participación y la incorporación de materiales:

Mo.- Empiezan a compartir los maestros la concientización para el uso de zapatos deportivos.

La participación de un profesor al compartir su experiencia, señala a la integración de los alumnos al proceso, así como a la toma de decisiones, de sus razones que justifican su actuar:

Mo.- Comparte su experiencias y cada quien tiene diferentes contextos y dice que se debe preguntar el por qué no pueden o no traen el uniforme, él les pide que lleven otro pants que no sea del uniforme pidiendo la autorización y la niña al finalizar la clase se cambia de ropa con el uniforme correspondiente.

Finalmente, el coordinador del trabajo pide al grupo el acuerdo que se acuerde como colectivo y el colectivo acuerda:

Continuar trabajando de acuerdo a los aspectos que se esperan en una clase para que el proceso enseñanza aprendizaje sea el óptimo y los alumnos puedan aprovechar de acuerdo a las características e intereses de cada uno de ellos.

La interconexión de estas imágenes genera en los profesores y directivos el sentido que la reunión va tomando.

\section{c).- Significados deducidos}

A continuación se describe las formas en que se presenta el significado deducido por los profesores y directivos en la interacción, significados que 
se forman y se reconstruyen con los símbolos que se generan en contexto interactivo, interpretado a través de los actos desarrollados en la acción.

Ma.-Pregunta que en el fondo del video hay unas pinturas y pide que le platique de qué se trata el proyecto.

La profesora sabe de qué se trata, pero en la interacción permea la generación de cuestionamientos con la intención de observar el comportamiento del expositor, lo que genera una interacción en que las expresiones de sentido de los profesores y directivos se manifiestan en una acción diádica que también tiene su significado desde la acción simbólica:

Mo.-Dice que lo felicita y refiere que él ya tiene 27 años de servicio y ve muchas caras nuevas.

Continúa diciendo y exaltando a la escuela y al profesor:

Mo.- termina diciendo que él conoció la escuela antes y que es grato ver el maravilloso cambio actual.

De tal forma que insiste en que el trabajo realizado por el profesor rebasa sus ámbitos de desarrollo, situación inmediata que los actores captan y de los cuales emergen los actos:

Ma.- Pregunta al maestro que si son horas extra clase y el maestro dice que no.

Nuevamente las imágenes que los profesores tienen sobre su actuar docente se hacen presentes, permitiendo que ellos manipulen el significado de acuerdo con lo que se debe de presentar y su discurso se incluyéndose al consenso de la participación y provocando influencias recíprocas en sus acciones.

\section{DISCUSIÓN DE RESULTADOS}

Las influencias recíprocas son el escenario que desarrolla la interacción colectiva, este comportamiento radica en la formulación alterna de indicaciones entre quienes intervienen en el proceso colectivo del Consejo Técnico Escolar, un proceso de “interconexión de la acción” (Blúmer, 1982).

Desde esta perspectiva asumimos que el significado es una producción social, producto de la interacción, creación que emana de y a través de las actividades definitorias de los participantes en el proceso. 
Hemos venido desarrollando que los profesores y directivos construyen en la interacción en el Consejo Técnico Escolar, una categorización de significados: establecidos, manipulados y deducidos.

Abordando a los significados establecidos como aquellos significados que las interacciones contienen en sí, para los profesores y directivos, y que constituyen un elemento central en sí mismo, de ahí que el ser humano oriente sus actos en relación con las cosas, basándose en el significado que estas le ofrecen.

Los miembros del colectivo saben lo que significa la guía de observación y la intención que ésta tiene, la discusión colectiva, las acciones interactivas realizan abordando este significado, como elemento central, la interacción que se genera, apunta siempre en esta dirección, cuando se refiere a la respuesta de las preguntas generan una interconexión de la acción produciéndose la adaptación reciproca de las acciones de cada uno de los participantes (Blumer,1982).

En este espacio se conforma también la identidad de los profesores y directivos, constituyéndose sobre la base de valores, pautas de comportamientos, actitudes y costumbres del colegiado, elementos que construyen la realidad de la que forman parte.

Los significados establecidos son aquellos que se han estructurado en los procesos de interacción y que le dan estructura cultural, son elementos de natural estructura, una guía de observación de clase, es una estructura objetiva que es inherente al hacer docente, elementos como el interés de los alumnos, retroalimentación, autonomía de los alumnos son significados manipulados, estructurados por la interacción social de los miembros del colegiado donde las definiciones encarnan en individuos concretos que son a su vez definidores de dicha realidad (Berger y Luckmann, 1967).

La utilización del significado por una persona del colegiado no es sino una aplicación de éste, cuando el profesor afirma que busca el interés de sus alumnos, no es sino la manipulación de los consensos en que los profesores y directivos saben a qué se refiere, estos permiten generar en el colegiado una distinción de su práctica, una interconexión de significados, porque la utilización en la acción de la interacción, no es sino la implicación de un proceso interpretativo (Blumer, 1969).

Así entonces, el interaccionismo simbólico pone énfasis en la interacción de los individuos y en la interpretación de las situaciones inmediatas, la interpretación por parte de los actores de los símbolos que emergen de los actos interactivos que son una dotación expresiva de simulaciones "la fachada" (Goffman, 1956).

La fachada es producto de la manipulación de significados: la manipulación del significado de la expresión "mis gustos son sus gustos", "la empatía, las 
barreras"; los docentes manipulan la realidad de su práctica, su actuación, contribuye a fijar la definición de la situación que intenta mostrar.

La fachada abarca dos elementos como son el medio, lo que está al margen de la persona; y la fachada personal, compuesta por "insignias del cargo o rango, pausas del lenguaje, las expresiones faciales, los gestos corporales y otras características semejantes" (Goffman, 1956: 35).

En la mayoría de los casos, el medio y la fachada personal convergen, porque el significado que es deducido en la interacción social, es aplicado en contexto, donde es aprovechado por algunos profesores para deducir su participación, para Goffman, la vida es como una representación teatral y consiste en actuaciones "performances", donde hay actores y público, por lo que lo representado en las presentaciones es concebido como real mientras dura la representación.

Las actuaciones en las presentaciones de los profesores y directivos, como actores emplean máscaras, lo que supone la creación de normas propias del contexto, es decir en esta representación teatral se manifiestan patrones de acción a las que los individuos adecuan su actuación.

El bagaje simbólico define la proyección de los profesores y directivos, y que proyectan in situ, constituyen la deducción de significados, para interaccionismo simbólico, cada situación de interacción se definen los significados en la acción.

Un proceso de ensamblaje de las actividades de sus miembros, constituyen la deducción de significados, cada situación de interacción se define a los profesores y directivos en grupo.

Los beneficios que fortalecen los ideales momentáneas o que perduran, constituyen una unidad dentro de la cual se realizan aquellos intereses de los participantes en la interacción, los profesores y directivos encuentran en este espacio de significados deducidos un lugar para manifestar sus intereses.

\section{CONCLUSIONES}

Los profesores y directivos comparten significados de los tres ámbitos: establecidos, manipulados y deducidos; establecidos cuando comparten la interacción y vierten sus normas y valores, este marco les permite la interacción, manipulados cuando en el grupo se busca figurar y con ello interconectar líneas de acción de la interacción simbólica; símbolos como los del deber ser del profesor; felicitaciones públicas para generar subgrupos de liderazgo, utilizan significados manipulando la imagen de quién los propone.

Los significados que los profesores comparten en la interacción, son un conjunto de imágenes radicales que dan vida al armazón que actúan de forma colectiva, siempre en las circunstancias que les ha tocado actuarlo y que podemos observar en los conceptos que se manejan en grupo y que 
todos participan de este significado, para unos la réplica, para otros la alabanza, mientras que para otros los símbolos que significan son los de tensar la interacción, estos son también los significados que comparten.

Los significados: establecidos, manipulados y deducidos tiene su punto de encuentro en el momento de la interacción que desarrolla el colegiado del consejo técnico escolar vierte el dialogo de la interacción con los demás en el que confronta posiciones dando nacimiento a un nuevo significado.

La acción social que genera la producción de sentido está encuadrada en la cultura escolar, entendida como las normas y valores que acogen los significados in situ y la estructura social del cual derivan los tipos de relaciones existentes en el colectivo. 


\section{REFERENCIAS}

Berger, P. y Luckmann, TH. (1972). La construcción social de la realidad. Buenos Aires., Amorrortu.

Blumer, H. (1982). El interaccionismo simbólico. Barcelona: Hora.

Edmond M. y Dominique P. (1992). La interacción social. Barcelona: Paidós.

Goffman, E. (1956, 2000). "Rubor y organización social”. En Díaz, Félix (ed.) (2000). Sociologías de la situación (pp.41.58), Madrid, Ediciones La Piqueta. Goffman, E. (1983,1991). Los momentos y sus hombres. Barcelona, Paidós.

Simmel, G. 2002 (1917). Cuestiones fundamentales de Sociología. Barcelona: Gedisa 